ANAEROBIC POWER PROFILES FOR TRACK AND FIELD

\author{
By \\ Michael J. Johnson \\ A Thesis submitted in Partial \\ Fulfillment of the Requirements for \\ The Master of Science Degree
}

Thesis Chair: Dr. Steven J. Albrechtsen

THE UNIVERSITY OF WISCONSIN-WHITEWATER

August 11, 2008 
The University of Wisconsin-Whitewater

Thesis Approved

Michael J. Johnson

Date: August 11, 2008

Committee Members: 


\section{ACKNOWLEDGEMENTS AND DEDICATION}

I would like to thank all of you for your wisdom and support:

My family, Gary, Jean, and John Johnson

Rebekah A. Nelson, the love of my life

Dr. Steven J. Albrechtsen, for developing my love of physiology

James Nickasch, the best role model I could ask for

All of my amazing student athletes at UW-Whitewater and Marshall High School

Steve Beacom, the best high school track coach in Wisconsin

Jeff Looze, the best high school cross country coach in Wisconsin

Steve Brown, your knowledge of strength and conditioning still amazes me

Rick Witt, for your guidance and wisdom 
TABLE OF CONTENTS

Chapter $\quad$ Page

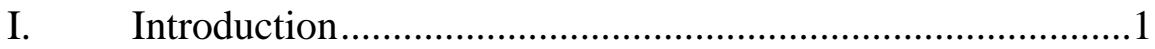

Who Needs Power Training? ......................................1

Training Power.............................................................

Anaerobic Training ....................................................

Importance of Anaerobic Training in

Aerobic Dominated Events .......................................6

Purpose of the Study ..................................................

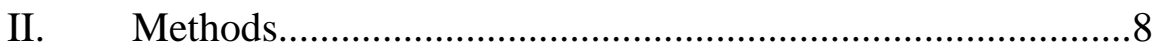

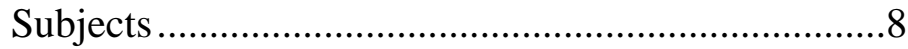

Apparatus ...............................................................

Procedures..............................................................

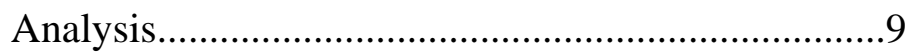

III. Results.............................................................................

IV. Discussion ..........................................................................16

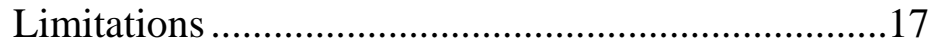

Practical Applications .................................................18

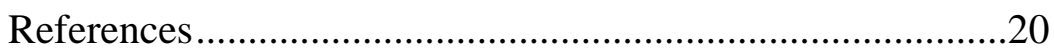




\section{LIST OF TABLES}

Table $\quad \underline{\text { Page }}$

1. Lower Body Power Parameters by Event Group ...................14

2. Upper Body Power Parameters by Event Group ...................14

3. Summary of Statistical Analysis by Event Group ................15 


\section{LIST OF FIGURES}

Figure $\quad$ Page

1. Energy System Usage ............................................................

2. Energy System Overview ………………………………....

3. Associated Fiber Type Distributions ……………………….....

4. $\quad$ Peak Power Lower Body versus Upper Body Power Outputs (Watts) by Event...........................................................10

5. Average Power Lower Body versus Upper Body Power Outputs (Watts) by Event..........................................................11

6. Power Drop Lower Body versus Upper Body Power Outputs (Watts) by Event.........................................................12

7. Minimum Power Lower Body versus Upper Body Power Outputs (Watts) by Event.........................................................13 


\author{
Abstract of Thesis \\ Michael J. Johnson \\ Anaerobic Power Profiles for Track and Field \\ August 11, 2008 \\ Dr. Steven J. Albrechtsen, Thesis Chair \\ The University of Wisconsin-Whitewater
}


Anaerobic Power Profiles for Track and Field

This research sought to determine the importance of lower and upper body muscular power in relation to performance in track and field events.

During the late competitive outdoor season, 32 male and female track and field athletes at an NCAA Division III institution were tested using a 30 second standard Wingate Anaerobic Test (WAT) on a Monarch cycle ergometer and a modified WAT on a Monarch cycle ergometer to measure lower body and upper body power, respectively. Prior to testing, the investigator collected data concerning age (yrs), height $(\mathrm{cm})$, weight (kg) and gender. Each track and field participant's personal records (PR's) were recorded for up to three of the subject's best events. Subjects then performed the standard WAT and modified WAT during a single exercise session. Data was then analyzed in Microsoft Excel spreadsheets to determine average performance and correlation relationships between power outputs and performance.

Correlation analyses were based upon the relationship between performance (PR in seconds or meters) and peak power, average power, minimum power, and power drop in W/kg for the standard and modified Wingate.

The data showed that the short sprint events presented power outputs that indicated a high level of anaerobic power (i.e., short sprints, sprint hurdles, jumps); whereas, longer sprints and middle-distance/distance events showed lower anaerobic power levels. 
Correlation analysis showed that subjects who participated in the short sprint events tend to have weaker correlations with respect to lower and upper body power for all variables (peak power, average power, minimum power, and power drop) when compared to subjects who participated in events of increasing distances. Short sprint event subjects showed moderate to strong correlations (0.3-0.8+), 800-meter event runners up to 5,000/10,000-meter event runners had nearly perfect correlations $(0.9+)$ in relation to lower and upper body anaerobic power. Vertical jumpers (high jump and pole vault) showed similar correlations to long sprinters (400-meters/400-meter hurdles); whereas, horizontal jumpers (long jump and triple jump) showed correlations similar to that of short sprinters.

The purpose of this study was to determine whether a significant amount of training should be spent developing anaerobic lower and upper body power depending on event specialization. The study indicated that while these variables are important, they are not single-handedly the main training factor. Subjects who participate in the power driven events demand high anaerobic power and more endurance driven events possess higher aerobic power. Training one energy system or another (i.e., aerobic versus anaerobic); is not the sole factor to determine performance. 


\section{CHAPTER I}

\section{INTRODUCTION}

\section{Who Needs Power Training?}

Coaches are always looking for the "magic formula" with which they can train their athletes to perform at a higher level over their competition. Each event has its own energy systems and requirements. It would be foolish to put a distance runner in the weight room doing only anaerobic work (i.e., squats at 85\% of repetition maximum) and, it would be equally foolish to discount this type of training entirely. The key to proper training is how much and how often it should be implemented.

When performing most activities, both energy systems, aerobic and anaerobic, are called upon in varying degrees. Consider the case of a 100-meter sprinter who depends on the energy-rich compounds of ATP (adenosine triphosphate) and PC (phosphocreatine) stored in the muscles which provide energy to explode down the track. A long distance runner, however, draws on anaerobic energy when sprinting at the finish of the race (10).

The amount of training time that should be applied to train each energy system can be systematically determined using an aerobic or anaerobic test. These tests reveal the amount of power output that is appropriate per event. Power is used to express work done in a unit of time or as the rate of performing work: Power $=$ Force $\bullet$ Distance $\bullet$ Time $^{-1}$ and is measured in Watts (W)(5). 


\section{Training Power}

Power and speed are the foundations of many track and field events. Training for these events should incorporate quick, explosive activities such as plyometrics, Olympic lifts, or short (up to 60-meters) fast sprints with long recoveries (9). Such activities incorporate high intensity activities which train neuromuscular patterns and increase motor unit recruitment. To get maximum results from power and speed training, there are numerous factors to consider above and beyond pure genetic potential (3). When determining how to train athletes, first consider the percentage of time during the event the athlete is either performing aerobic or anaerobic work. (See Figure 1.)

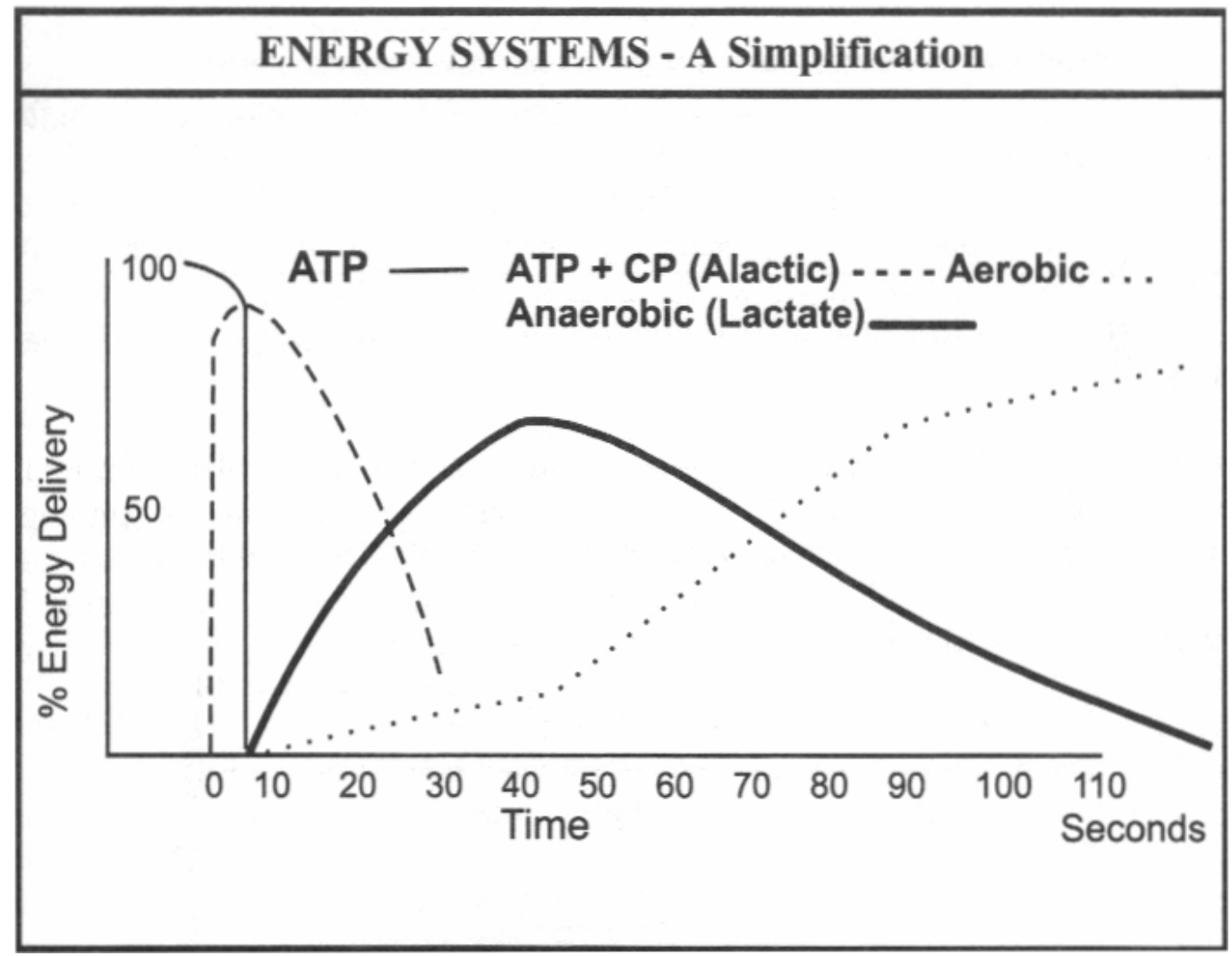

Figure 1 - Energy System Usage (9) 
For example, in the case of running training, a coach will want to understand the athlete's anaerobic threshold. The anaerobic threshold is the level of work beyond which the body can no longer generate energy quickly enough in an aerobic state to meet the demand of work. At this point, the body turns to anaerobic metabolism for continued, yet short lived, energy supplies (5). The anaerobic threshold can be determined in various ways using heart rate, $\mathrm{VO}_{2 \mathrm{MAX}}$, percentage of working pace or subjectively through a MET or RPE scale (7). These methods could be used to determine at what pace (i.e., time per mile based on heart rate in beats per minute) a beginning runner could work at aerobically in order to control pace as to not become anaerobic.

Having an understanding of where the anaerobic threshold will occur allows training to be designed to develop capacities, below, at or above the anaerobic threshold. For example, when performing a workout for a high level distance runner, working at 87\% of maximum heart rate (MHR) may not provide anaerobic training since a high level distance runner's anaerobic threshold is higher due to their high aerobic capacity. Additionally, performing sprint training at $90-100 \%$ of working pace could be considered speed training with long recoveries or speed endurance training with shorter recoveries (13). (See Figure 2.) 


\begin{tabular}{|c|c|c|c|c|c|c|c|}
\hline \multicolumn{7}{|c|}{ ENERGY SYSTEM OVERVIEW } \\
\hline $\begin{array}{c}\text { Energy } \\
\text { System }\end{array}$ & $\begin{array}{c}\text { Anaerobic } \\
\text { Alactic } \\
\text { (ATP } \\
\text { CP) }\end{array}$ & \multicolumn{3}{|c|}{$\begin{array}{c}\text { Anaerobic Lactic } \\
\text { (Glycolosis) }\end{array}$} & \multicolumn{2}{c|}{$\begin{array}{c}\text { Shared } \\
\text { Lactic/Aerobic }\end{array}$} & $\begin{array}{c}\text { Aerobic } \\
\text { (Krebs Cycle) }\end{array}$ \\
\hline Component & Speed & $\begin{array}{c}\text { Speed } \\
\text { Endurance }\end{array}$ & $\begin{array}{c}\text { Speed } \\
\text { Endurance } \\
1\end{array}$ & $\begin{array}{c}\text { Speed } \\
\text { Endurance } \\
2\end{array}$ & $\begin{array}{c}\text { Tempo } \\
\text { (Intensive) }\end{array}$ & $\begin{array}{c}\text { Tempo } \\
\text { (Extensive) }\end{array}$ & $\begin{array}{c}\text { Tempo } \\
\text { (Continuous) }\end{array}$ \\
\hline Intensity & $95-100 \%$ & $95-100 \%$ & $95-100 \%$ & $95-100 \%$ & $80-90+\%$ & $60-80 \%$ & $40-60 \%$ \\
\hline Time & $7 \mathrm{sec}$ & $7-20 \mathrm{sec}$ & $20-40 \mathrm{sec}$ & $\begin{array}{c}40 \text { sec }-2 \\
\text { Min }\end{array}$ & $\begin{array}{c}40 \text { sec }-2 \\
\text { min }\end{array}$ & $\begin{array}{c}40 \text { sec-2 } \\
\text { min }\end{array}$ & 2 min + \\
\hline
\end{tabular}

Figure 2 - Energy System Overview (Modified from McFarlane) (9).

Anaerobic Training

The anaerobic parameters in track and field are generally applied to events that seek to utilize the ATP-CP, alactate, or lactate energy systems during the activity. In these events, pure speed and power dominates the training theory. Athletes must possess the ability to use a combination of antagonist muscle groups working together, not simultaneously, but in sequence (11). This applies to every event from the short sprints and sprint hurdles, to jumps, to the kick at the end of the 5,000-meter run. Along with designing a training plan for any event, it is equally important to understand the fiber types the athlete will utilize in his/her event. (See Figure 3.)

Athletes who dominate the short sprints, jumps and throws have a higher percentage of “fast-twitch" muscle fibers (type IIb). These muscle fibers operate quickly and powerfully, yet their power output is short-lived since they rely on anaerobic metabolism. Eight hundred meter runners and race walkers possess more "slow-twitch" muscle fibers (type I). These muscle fibers have long duration abilities since they receive their energy from aerobic metabolism (5). 


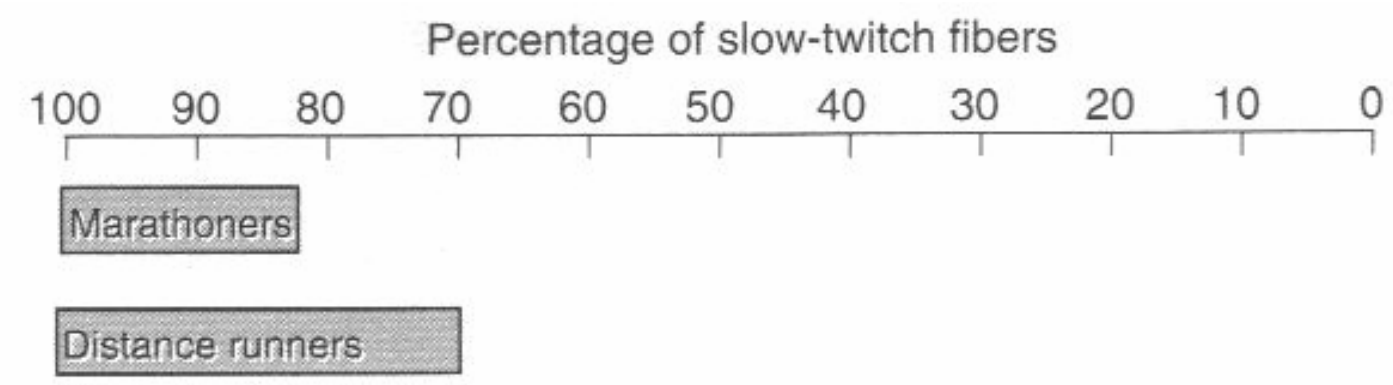

Bace walkers
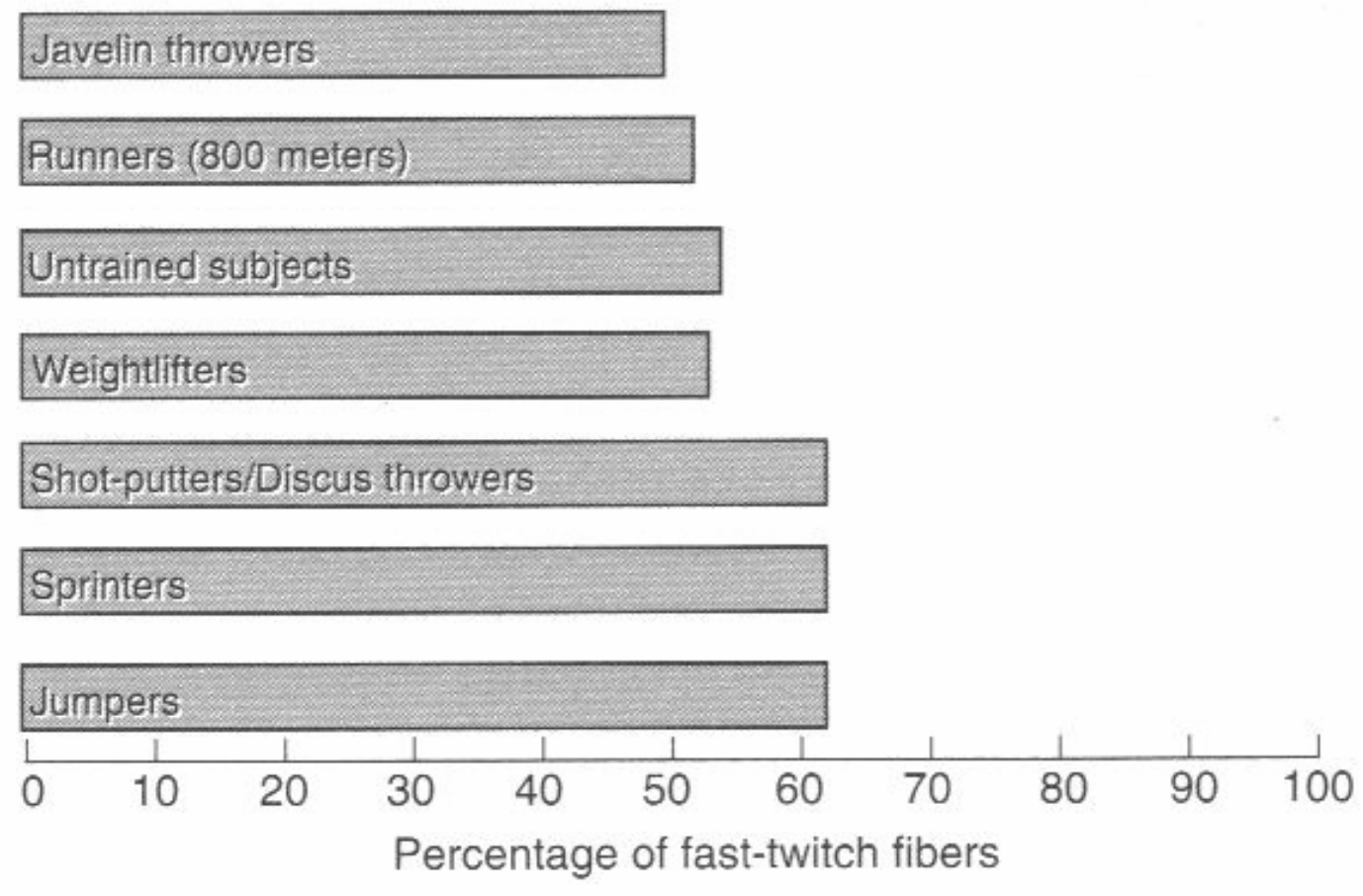

Figure 3 - Associated Fiber Type Distributions (2).

The aspect of aerobic training in "fast-twitch" dominated events cannot be ignored. The annual training plan should include a general preparation period for close to $30 \%$ of the total training time (usually 2.5 to 4 months depending upon the number of competition cycles) (12). 
The prescription of activities that are appropriate during the general preparation period based for sprinters should emphasize high volume, low intensity activities. Several popular methods are: general strength lifting programs with an emphasis on Olympicstyle lifts, sled pulls over 30-40-meters, hill sprints with a sprint-up, walk-down format and runs such as $6 \times 100$-meters at $70 \%$ of race pace with 30 seconds rest (6).

Once a solid base of aerobic conditioning has been established, the training plan can progress into a more specific style of training regime. Emphasis must be placed on activities that seek to enhance and refine the power and speed characteristics of the event. Importance of Anaerobic Training in Aerobic Dominated Events

Aerobic training will dominate the training landscape for runners who rely more on their aerobic capacity to succeed in their respective events. Runners will incorporate several months of base training over the summer and usually during their cross country season before competing in track and field. Runs of 6 to 20 miles in a workout, sometimes twice a day, will be performed early in the training cycle. The goal of this training is to allow the athlete to be able to train below their anaerobic threshold pace, which will increase as training effect occurs. However, this type of training cannot be the substitute for "kick" and "surge” types of tactics that are important to success in aerobicbased races. Hill training, fartlek runs, and short sprints are all options in a training repertoire that are done to enhance speed. It is debated whether strength training plays a viable role in aerobic based events (14). 
Purpose of the Study

There is much published literature that studies the $\mathrm{VO}_{2 \mathrm{MAx}}$ of a marathon runner or the anaerobic power of a sprinter. However, little research is available that seeks to show the amount of anaerobic work that should be implemented across a wide variety of events in track and field.

The purpose of this study was to determine the level of anaerobic power across several track and field events and then to determine the percentage of training that should be dedicated to anaerobic versus aerobic training efforts for each event. In addition, a coach or trainer can determine how much time not to spend on a certain type of training, given the tested physiological implications. 


\section{CHAPTER II}

\section{METHODS}

\section{Subjects}

American Division III track and field student-athletes who were members of an NCAA institution were invited to participate in this research project. Male and female athletes competing in a broad range of track and field events were approached and asked to volunteer for a study of performance in their events based on upper and lower body power. Testing was done outside of scheduled practice times in a laboratory setting. Subjects were 4 females and 28 males who were healthy, college student-athletes who were currently participating in physical activity on a regular basis and were previously cleared for activity through a physical examination required for participation in intercollegiate athletics. The subject's competitive backgrounds included from one to four years in collegiate track and field.

Apparatus

Lower body power was measured by means of a Monarch cycle ergometer with a computer interface to measure power output. Upper body power was measured with a modified Monarch cycle ergometer and computer interface. For the upper body portion of the test, cycle ergometer pedals were removed and replaced with pedal posts covered in padding. The cycle ergometer was secured to the top of a laboratory table (4). Procedures

Prior to testing, the subjects signed informed consent and completed the Physical Activity Readiness Questionnaire (PAR-Q) developed by the Canadian Society of 
Exercise Physiology with support from Health Canada (1). The purpose of the experiment was explained to each subject. Information on each subject was collected concerning age (yrs), height $(\mathrm{cm})$, weight $(\mathrm{kg})$ and gender. Each track and field participant's personal records (PR's) were recorded for up to three of the subject's best events. The participants performed a single standard Wingate test and a single modified Wingate test.

A force setting for the standard Wingate test of $7.5 \%$ of body weight was used for the lower body anaerobic power test. A force setting for the modified Wingate test of $2.5 \%$ of body weight was used for the upper body anaerobic power test. The settings were rounded to the nearest $0.5 \mathrm{~kg}$ to determine the actual force setting.

Both tests were performed in a single exercise session. The lower body anaerobic power test was performed first. The subject was allowed to fully recover for five to 15 minutes by walking and determining their resting recovery based on a RPE type scale reading (7). The upper body anaerobic power test was performed following recovery. Analysis

After testing procedures were completed, each subject’s peak anaerobic power, average anaerobic power, minimum anaerobic power, and anaerobic power drop were calculated for both tests. Subjects were divided up by each event which was determined by the information the subjects provided. Data was then analyzed in Microsoft Excel spreadsheets to determine average performance and correlation relationships between power outputs and performance. 


\section{CHAPTER III}

\section{RESULTS}

Figures $4-7$ show the power outputs for both standard and modified Wingate anaerobic tests. Each individual variable is represented (peak power, average power, power drop, and minimum power). Data points are based upon the average value of the test subjects of each event group. Subjects submitted up to their top three performances in events. Each subject's performances therefore, may fall into more than one event group’s data.

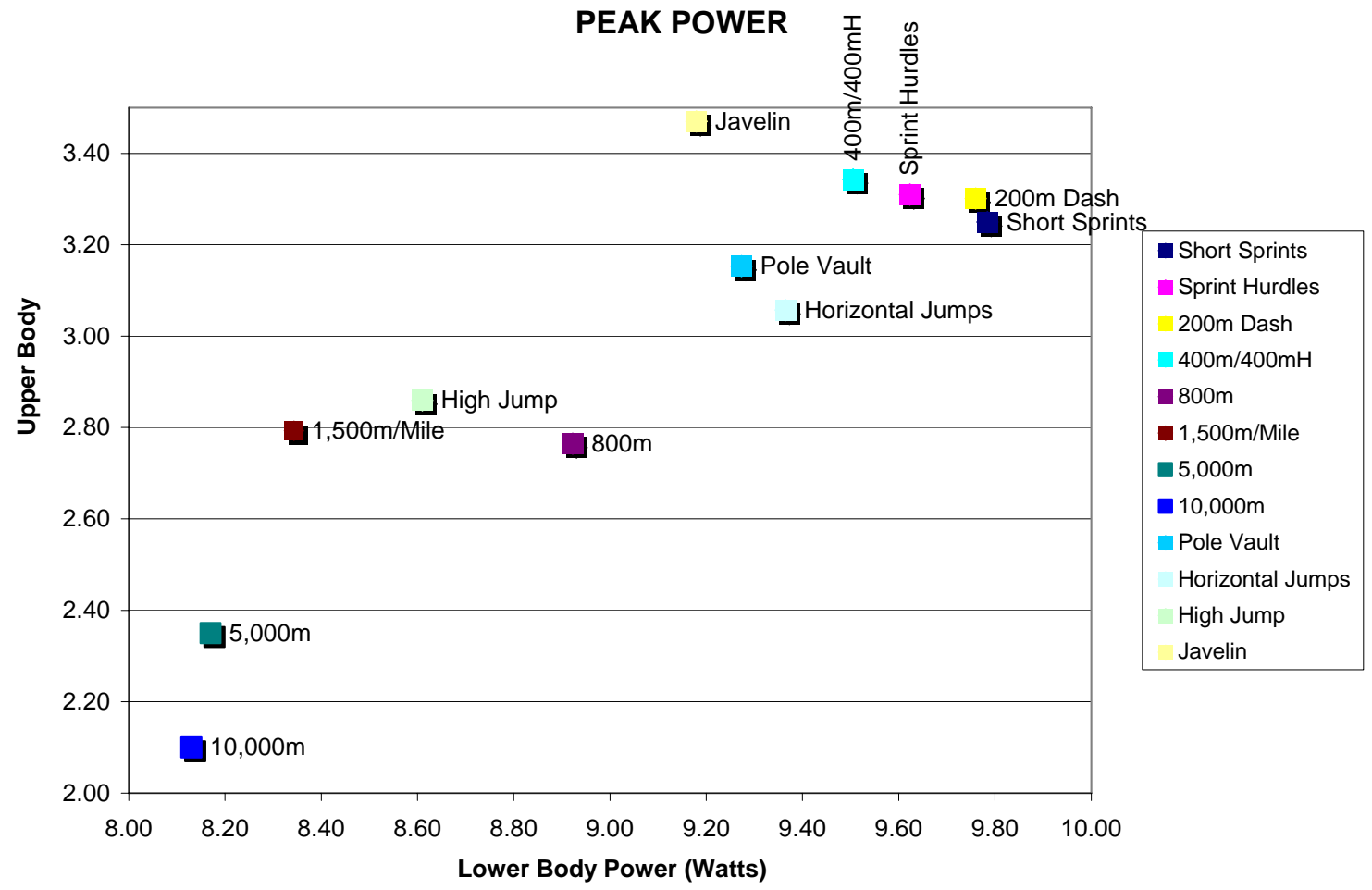

Figure 4 - Peak Power Lower Body versus Upper Body Power Outputs (Watts) by Event 


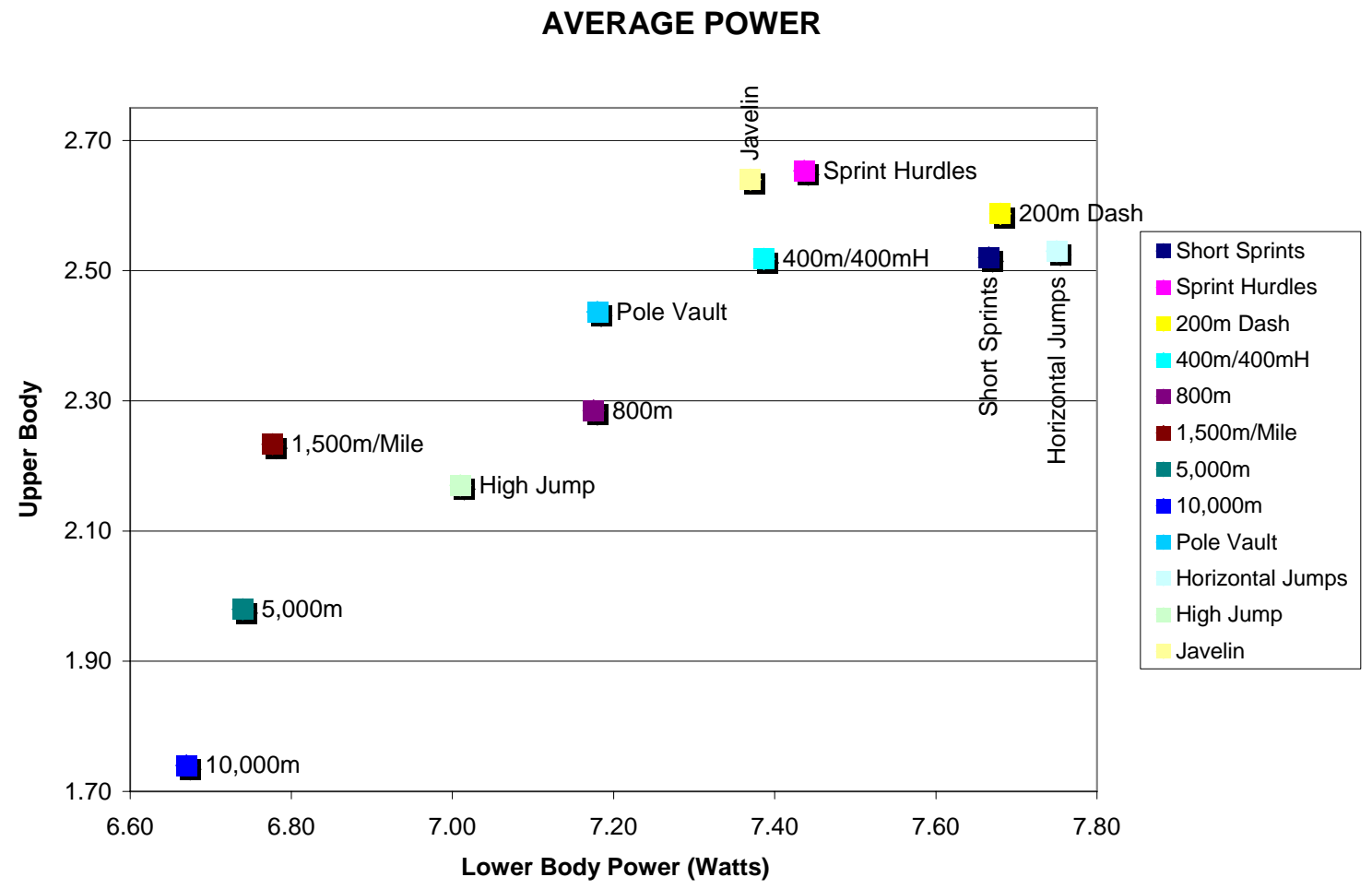

Figure 5 - Average Power Lower Body versus Upper Body Power Outputs (Watts) by Event 


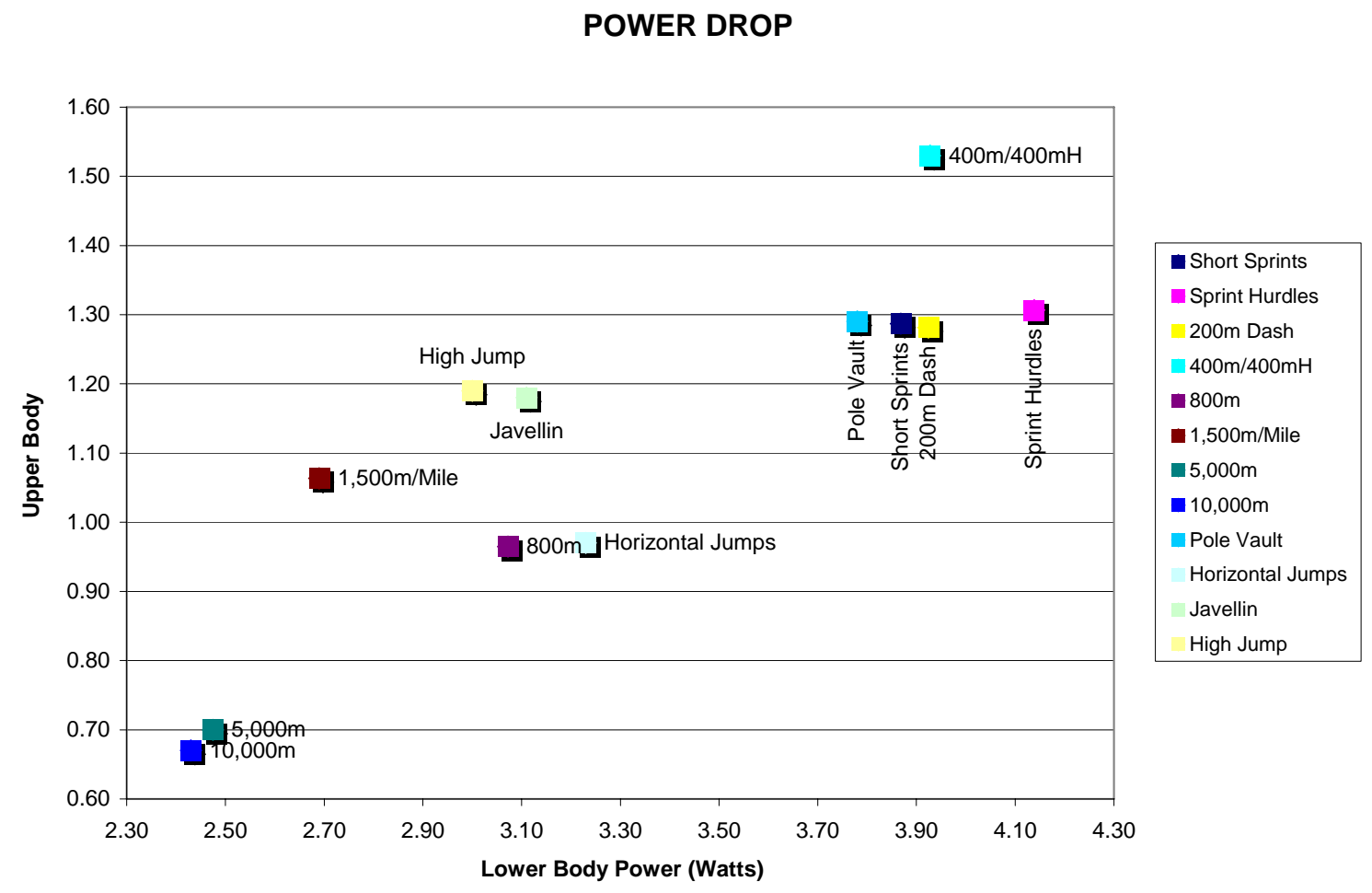

Figure 6 - Power Drop Lower Body versus Upper Body Power Outputs (Watts) by Event 


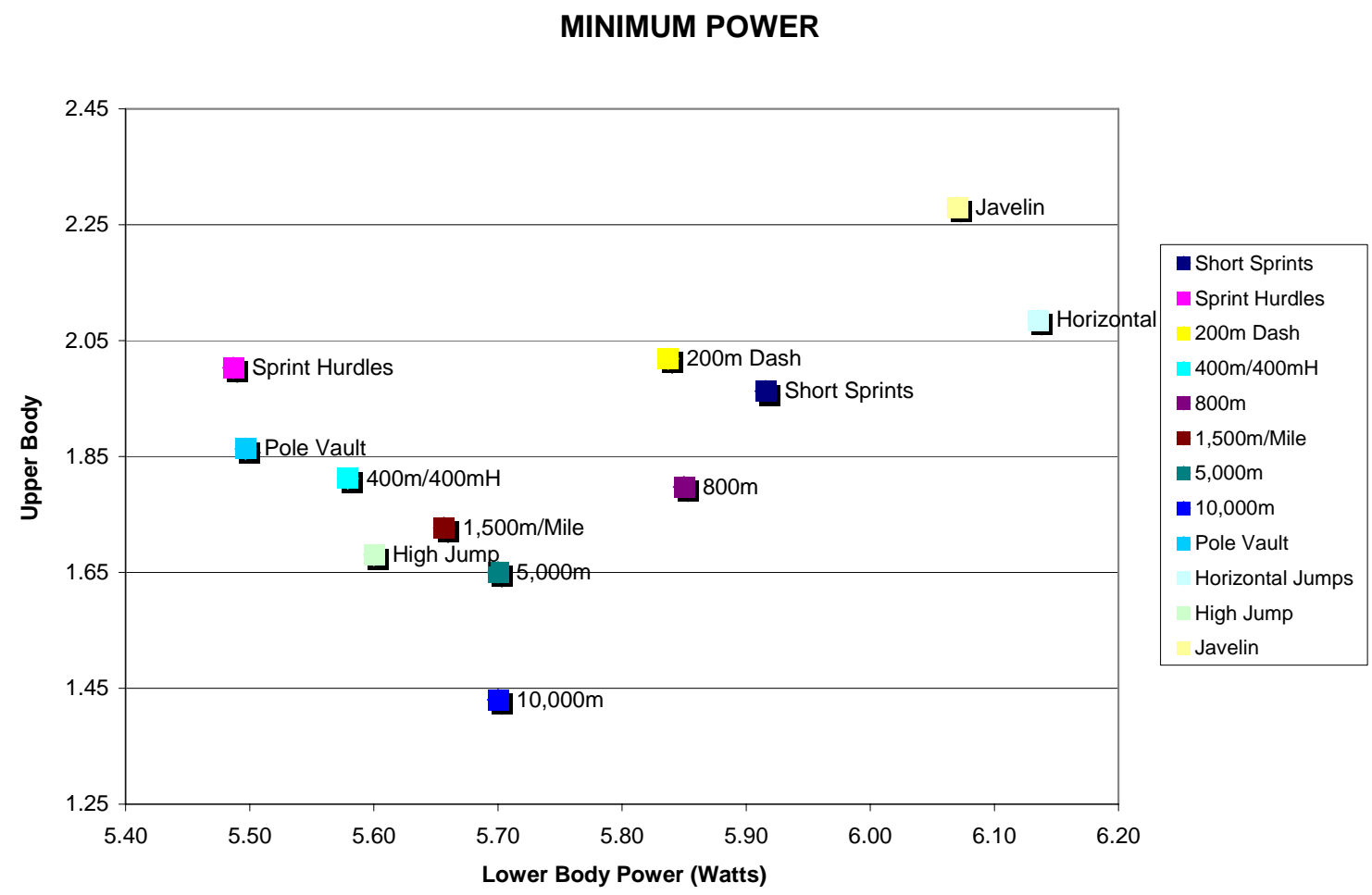

Figure 7 - Minimum Power Lower Body versus Upper Body Power Outputs (Watts) by Event

Table 1 shows the average lower body anaerobic power variables of peak power (Pk Pwr), average power (Avg Pwr), minimum power (Min Pwr), and power drop (Pwr Drop) by event. Table 2 shows the average upper body anaerobic power variables of peak power (Pk Pwr), average power (Avg Pwr), minimum power (Min Pwr), and power drop (Pwr Drop) by event. Table 3 shows the correlation analysis for both lower body and upper body parameters by event.

The strengths of meaningfulness for correlation according to Hopkins and Cohen are as follows: trivial (0.0), small (0.1), moderate (0.3), strong (0.5), very strong (0.7), nearly perfect (0.9), and perfect (1.0). 
Table 1. Lower Body Power Parameters by Event Group

\begin{tabular}{l|llll}
\hline LOWER BODY & Avg Pk Pwr & Avg Avg Pwr & Avg Min Pwr & Avg Pwr Drop \\
\hline Short Sprints (n = 7) & $9.78(\mathrm{~W} / \mathrm{kg})$ & $7.67(\mathrm{~W} / \mathrm{kg})$ & $5.92(\mathrm{~W} / \mathrm{kg})$ & $3.87(\mathrm{~W} / \mathrm{kg})$ \\
Sprint Hurdles $(\mathrm{n}=6)$ & 9.62 & 7.44 & 5.49 & 4.14 \\
200m $(\mathrm{n}=7)$ & 9.76 & 7.68 & 5.84 & 3.92 \\
$400 \mathrm{~m} / 400 \mathrm{mH}(\mathrm{n}=9)$ & 9.51 & 7.39 & 5.58 & 3.93 \\
$800 \mathrm{~m}(\mathrm{n}=4)$ & 8.92 & 7.18 & 5.85 & 3.07 \\
$1,500 \mathrm{~m} /$ Mile $(\mathrm{n}=3)$ & 8.34 & 7.18 & 5.66 & 2.69 \\
$5 \mathrm{k} / 10 \mathrm{k}(\mathrm{n}=2)$ & 8.17 & 6.74 & 5.70 & 2.48 \\
Vert. Jumps $(\mathrm{n}=4)$ & 9.11 & 7.14 & 5.52 & 3.59 \\
Horiz. Jumps (n=4) & 9.37 & 7.75 & 6.14 & 3.23 \\
\hline Overall Average & $\mathbf{9 . 1 8}$ & $\mathbf{7 . 3 1}$ & $\mathbf{5 . 7 4}$ & 3.43 \\
\hline
\end{tabular}

( $\mathrm{n}=$ number of test subjects)

Table 2. Upper Body Power Parameters by Event Group

\begin{tabular}{l|llll}
\hline UPPER BODY & Avg PkPwr & Avg Avg Pwr & Avg Min Pwr & Avg Pwr Drop \\
\hline Short Sprints $(\mathrm{n}=7)$ & $3.25(\mathrm{~W} / \mathrm{kg})$ & $2.52(\mathrm{~W} / \mathrm{kg})$ & $1.96(\mathrm{~W} / \mathrm{kg})$ & $1.29(\mathrm{~W} / \mathrm{kg})$ \\
Sprint Hurdles $(\mathrm{n}=6)$ & 3.31 & 2.65 & 2.00 & 1.31 \\
200m $(\mathrm{n}=7)$ & 3.30 & 2.59 & 2.02 & 1.28 \\
$400 \mathrm{~m} / 400 \mathrm{mH}(\mathrm{n}=9)$ & 3.34 & 2.52 & 1.81 & 1.53 \\
$800 \mathrm{~m}(\mathrm{n}=4)$ & 2.77 & 2.29 & 1.80 & 0.97 \\
$1,500 \mathrm{~m} /$ Mile $(\mathrm{n}=3)$ & 2.79 & 2.23 & 1.73 & 1.06 \\
$5 \mathrm{k} / 10 \mathrm{k}(\mathrm{n}=2)$ & 2.35 & 1.98 & 1.65 & 0.70 \\
Vert. Jumps $(\mathrm{n}=4)$ & 3.08 & 2.37 & 1.82 & 1.27 \\
Horiz. Jumps $(\mathrm{n}=4)$ & 3.06 & 2.53 & 2.09 & 0.97 \\
\hline Overall Average & $\mathbf{3 . 0 3}$ & $\mathbf{2 . 4 1}$ & $\mathbf{1 . 8 7}$ & $\mathbf{1 . 1 5}$ \\
\hline
\end{tabular}

$(\mathrm{n}=$ number of test subjects $)$ 
Table 3. Summary of Statistical Analysis by Event Group

\begin{tabular}{l|llllllll}
\hline & $P P(L B)$ & $P P(U B)$ & $A P(L B)$ & $A P(U B)$ & $M P(L B)$ & $M P(U B)$ & $P D(L B)$ & $P D(U B)$ \\
\hline SS & -0.36 & -0.69 & 0.39 & 0.00 & 0.51 & 0.56 & -0.65 & -0.78 \\
SH & 0.68 & -0.07 & 0.06 & 0.03 & -0.38 & 0.09 & 0.81 & -0.08 \\
$200 \mathrm{~m}$ & 0.59 & -0.20 & 0.64 & -0.24 & 0.80 & 0.52 & 0.02 & -0.28 \\
$400 \mathrm{~m}$ & 0.51 & -0.01 & 0.80 & 0.40 & 0.74 & 0.73 & 0.01 & -0.33 \\
$800 \mathrm{~m}$ & 0.90 & -0.06 & 0.91 & 0.96 & 0.94 & 0.68 & 0.83 & -0.55 \\
$1500 \mathrm{~m}$ & 0.93 & 0.34 & 0.97 & 0.92 & 0.98 & 0.39 & 0.88 & 0.09 \\
$5 \mathrm{k} / 10 \mathrm{k}$ & -1.00 & -1.00 & -1.00 & -1.00 & $\mathrm{ND}$ & -1.00 & -1.00 & -1.00 \\
VJ & -0.46 & 0.75 & -0.85 & -0.38 & -0.51 & -0.72 & 0.21 & 0.79 \\
HJ & -0.37 & 0.09 & 0.26 & 0.57 & 0.78 & 0.10 & -0.72 & 0.11 \\
\hline Average & $\mathbf{0 . 1 6}$ & $\mathbf{- 0 . 0 9}$ & $\mathbf{0 . 2 4}$ & $\mathbf{0 . 1 4}$ & $\mathbf{0 . 4 8}$ & $\mathbf{0 . 1 5}$ & $\mathbf{0 . 0 4}$ & $\mathbf{- 0 . 2 3}$ \\
\hline
\end{tabular}
(ND = no data available)

Correlation analysis was performed comparing each individual power parameter to a point value set by the International Association of Athletics Federations (IAAF). The point value was obtained from scoring tables provided by the IAAF which assess a point value based on performance (8). The IAAF has determined point values similar to that seen in a decathlon scoring system for each event in track and field. In this case, the athlete’s personal records which they submitted prior to testing were used.

The data shows correlations which represent moderate (0.3) to very strong (0.7) for anaerobic lower and upper body power in the short sprints and horizontal jumps. As distance increases, correlations increase for both lower and upper body anaerobic power to very strong $(0.7)$ and nearly perfect $(0.9+)$. This trend is also seen in the vertical jumps. Distances in the 5,000-meters (5k), and 10,000-meters (10k), were not significant, due to the lack of a sufficient number of subjects. 


\section{CHAPTER IV}

\section{DISCUSSION}

The graphs that represent averages per event group show the relationship of lower and upper body power for subjects in each event group. The graphs show higher power outputs for both lower and upper body anaerobic power in power and speed dominated events like the short sprints, sprint hurdles, and jumping events. As event distance increases, the power output decreases for both lower and upper body power in events such as the 800-meters and up.

By using the standard Wingate and modified Wingate test, data can be collected that will determine the correlation between lower and upper body anaerobic power outputs and performance. Using these results, a coach or trainer will be able to determine the amount of effort to focus training with respect to lower body and upper body strength and/or power. This can be significant in many training plans. By eliminating effort spent training irrelevant aerobic or anaerobic power, an athlete is able to focus on training that will provide more benefit during the season.

Power parameters in the short sprints showed only moderate correlation between peak power and performance in the lower body. However, correlations became strong to very strong concerning average power, minimum power, and power drop in both lower and upper body. One might conclude that in this sample group, the sprinters were able to perform using their endurance rather than initial explosive power. Interestingly, sprint hurdlers showed a broad range of correlations in power performance for both lower and 
upper body. However, their peak power in the lower body was significantly stronger than that of the short sprinters. This suggests that high levels of explosive training that lead towards an explosive start may set the tone for successful sprint hurdling.

Also noteworthy is the fact the both lower and upper body correlations seem to peak with respect to 800-meters/1,500-meters and Mile runners. Both lower and upper and body parameters showed strong to nearly perfect correlations. This suggests an equal amount of training time should be spent with lower and upper body power in endurance activities.

Athletes who primarily participate in the pole vault represent similar correlations for lower and upper body power correlations as did the 800/1,500-meters and Mile runners. This reinforces that a pole vaulter should be significantly powerful in both lower and upper body to be successful.

Horizontal jumpers represented correlations similar to that seen in the short sprinters. Lower body peak power, for example, was low; however the remaining parameters were significantly higher.

The data demonstrates that power and speed events benefit athletes who have high anaerobic power. Concurrently, distance runners have a tendency to have high aerobic power. However, as seen with the data in Table 3, these are not the only variables when considering training.

\section{Limitations}

While this study represented a wide range of events in track and field, the individual event groups contained small numbers of participants which limits the 
conclusions that may be drawn. The data should not be ignored, however, as these may be important indicators in performance and could lead to further, more in-depth studies in the future.

The abilities of subjects were also on a broad spectrum in relation to performance. The data may cloud the fact that some subjects in this group were All-Americans; and may not fairly represent their correct lower and upper body power outputs with respect to their performances since data were based on averages.

Additionally, no data was obtained from athletes in the throwing events.

Throwing events are heavily anaerobic in nature and data from these individuals may also give more accurate insight into a stronger conclusion. One subject who competed in the javelin was tested, but the small sampled size cannot lead to a strong conclusion.

This study only looked at NCAA Division III athletes, studies of higher level athletes, such as Division I athletes, may tell a completely different story.

\section{Practical Applications}

As with every track and field event, there is no magic "recipe for success" to make all athletes perform equally within an athletes respective event group. It is important to be familiar with a broad range of information and training tactics in order to fit each individual athlete’s needs.

The subjects in this group were all trained under different training methods with their own emphasis. The respective coach will train their group with different goals in mind. This research suggests that there are indicators present that may benefit training of athletes more or less with respect to lower and upper body output. 
The most encouraging part of this data is that it can be used in a broad range of training areas: on track training, pre-season, strength and conditioning, plyometrics, endurance, etc. Take your pick, and you will be able to work this useful information into your training program.

As mentioned earlier, these are only indicators of the different types of training with respect to lower body and upper body power and their implications. Ignoring studies such as this may be counter-productive to training.

This study lays a certain amount of ground work for future studies. Studies in the future would seek to incorporate a higher number of test subjects with a wider range of abilities, including elite athletes, from each event group. Avenues to be explored could include testing of other variables that may lead to a more concrete conclusion. This study also challenges the notion of significant effort spent on resistance exercise which leads to higher performances. 


\section{REFERENCES}

1. Armstrong, L., Balady, G.J., Berry, M.J., Davis, S.E., Davy, B.M., Davy, K.P., et al. ACSM's guidelines for exercise testing and prescription. $7^{\text {th }}$ edition.

Philadelphia: Lippincott Williams \& Wilkins; 2006. p. 26.

2. Bompa, T.O., \& Carrera, M.C. Periodization training for sports. $2^{\text {nd }}$ edition. Champaign: Human Kinetics; 2005. p. 18.

3. Brown, L.E., \& Ferrigno, V.A. Training for speed, agility, and quickness. $2^{\text {nd }}$ edition. Champaign: Human Kinetics; 2005. p. 18.

4. Cook, M.K. Muscular power (upper and lower body) and performance in the hammer throw. Unpublished masters thesis; 2006. p. 9.

5. Foss, M.L., \& Keteyian, S.J. Fox's physiological basis for exercise and sport. $6^{\text {th }}$ edition. Boston: McGraw-Hill; 1998. p. 76, 143, 182.

6. Guthrie, M. Coaching track \& field successfully. Champaign: Human Kinetics; 2003. p. 74.

7. Heyward, V.H. Advanced fitness assessment \& exercise prescription. $3^{\text {rd }}$ edition. Champaign: Human Kinetics; 1998. p. 90.

8. IAAF.org. International association of athletics federations: scoring tables. (Retrieved May 28, 2008, from http://www.iaaf.org/search/index.htmx?q=scoring+tables

9. McFarlane, B.A. The science of hurdling and speed. $4^{\text {th }}$ edition. Ontario: Minuteman; 2000. p. 83-84, 93.

10. McGlynn, G.H., \& Moran, G.T. Cross-training for sports. Champaign: Human Kinetics; 1997. p.14.

11. Sandler, D. Sports power. Champaign: Human Kinetics; 2005. p. 6.

12. U.S.A. Track \& Field Coaching Education Curriculum. Level II sports science; 2007. p. 21

13. U.S.A. Track \& Field Coaching Education Curriculum. Level II sprints/hurdles/relays; 2007. p. 59. 
14. Wallace, E.L., Jr. Track \& field coach’s survival guide: Practical techniques and materials for building an effective program and success in every event. Mira Loma: Parker; 1998. p.156. 